\title{
Similarities and differences in values between Vietnamese parents and adolescents
}

\begin{abstract}
BACKGROUND
The purpose of this study was to analyse similarities and differences in the motivational value system of Vietnamese parents and adolescents, in the context of Schwartz's value theory. Also, the transmission of values between two generations was studied.
\end{abstract}

\section{PARTICIPANTS AND PROCEDURE}

The study was performed in three different cities of Vietnam - Hanoi, Hue and Ho Chi Minh City - on adolescents, their fathers and mothers $(N=2226)$. The hierarchy of values was measured with a Vietnamese version of the Portrait Value Questionnaire (PVQ-40). Additionally, expectations of parents toward children and preferences of children were measured with a list of 28 features and attitudes prepared for the study.

\section{RESULTS}

The results show that both parents and their adolescent children highly respect universalism, conformity, and be- nevolence in contrast to power and stimulation, which is still typical for a collectivistic culture. The differences arise in higher-order values: while parents value conservatism (security, conformity and tradition), their children prefer more openness to change (self-direction and hedonism) values, which is typical for a more individualistic culture. The results also reveal that parents in Vietnam expect and transfer to children some attitudes and features such as studiousness, filial piety and diligence, but not riskiness, desire or humour. Although adolescents are aware of their parents' expectations, they do not fully accept them.

\section{CONCLUSIONS}

The results provide hints for parents to plan their strategy on appropriate education of their children, in the current context of global integration and cultural changes.

\section{KEY WORDS}

Schwartz's basic values; parents and adolescents; Vietnam

ORGANIZATIONS - 1: VNU University of Social Sciences and Humanities in Hanoi, Vietnam · 2: Institute of Psychology,

University of Gdansk, Gdansk, Poland

Authors' CONTRibution - A: Study design - B: Data collection - C: Statistical analysis - D: Data interpretation .

E: Manuscript preparation · F: Literature search · G: Funds collection

CORRESPONDING AUTHOR - Prof. Truong Thi Khanh Ha, University of Social Sciences and Humanities in Hanoi,

336 Nguyen Trai, Thanh Xuan, Hanoi, Vietnam, e-mail: ttkha@vnu.edu.vn

To Cite this ARTICLE - Khanh Ha, T. T., Van Luot, N., \& Różycka-Tran, J. (2015). Similarities and differences in values

between Vietnamese parents and adolescents. Health Psychology Report, 3(4), 281-291. DOI: 10.5114/hpr.2015.51933

RECEIVED 10.04.2015 - REVIEWED 09.05.2015 · ACCEPTED 13.05.2015 · PUBLISHED 10.07.2015 


\section{BACKGROUND}

\section{VALUE TRANSMISSION}

Values are the directional principles in people's lives, the general objects which regulate people's actions (Schwartz, 1992). Therefore, each society and family pays a lot of attention to transmitting virtues and good values to the next generation. This is especially so in a collectivistic country, where interactions and
Truong Thi

Khanh $\mathrm{Ha}$, Nguyen Van Luot, Joanna Różycka-Tran the social duty network play an important role in the functioning of society.

Vietnamese identities have been formed over thousands of years, having been passed down through many generations. According to Tran Dinh Huou (1994), Vietnamese people tend to be concerned with and care about their children more than themselves; they also respect community and do not honour the idea of individualism and self-reliance. For that reason, there is a high agreement between Vietnamese parents and their children. Based on Grusec and Goodnow (1994), such a positive relationship quality should increase children's willingness to comply with parental wishes. However, adolescents are also affected by the general movement in the current context of integration and development, which is becoming more and more open, expanded by the internet and television. These cultural changes reflect the youth's trend in the changing value system. Conflicts arising between parents and their adolescent children originate from the conflict of values between the two generations.

Adolescence is the stage where the individual character develops strongly, featured by the struggle between the desire for independence and the obligation to follow social expectations (Padilla-Walker, 2007). Therefore, the acceptance of values in adolescence is much more conflictive and selective than during childhood. Before finishing building a stable system of values for themselves, adolescents often discover values of parents and friends, evaluate and compare them to each other, and to other systems of values in the society. Thus, parents' opinions and values play important roles in forming children's individual character (Marcia, 1966).

The research of Knafo and Schwartz (2001, 2004) showed high relativity between values that parents want for themselves and those that they want their children to have. However, the process of "transmitting" the value system from parents to children, also called the value transmission, is affected by many factors. Researchers have shown that the process of "transmitting" values or beliefs from parents to children is not a one-way process. It is a complicated two-way process, controlled by the characters of both parents and children (Kuczynski, Marshall, \& Schell, 1997). The educating style of parents may influence the children's ability to be aware of values and accept them; meanwhile, children also actively evaluate these values and choose whether or not to accept the values transmitted from parents.

The two-step model of Grusec and Goodnow (1994) is the application of Erikson's theory (1968) and Marcia (1966, 1980), related to the character formation and value acceptance of adolescents. This model emphasizes the positive role of both parties: parents and children. Firstly, children have to be aware of values that their parents encourage. After that, they have to accept these values as their own values. Thus, although parents are value transmitters, adolescents are the ones who accept these values to create value agreement between parents and children (Grusec \& Goodnow, 1994). The value transmission can be successful or fail: In the first step, children may identify the values their parents want to transmit as right or wrong; in the second step, the children's choice may be to accept or to reject these values. If the children identify one of their parents' values as right and accept it, the level of value agreement between parents and children will be high, as has been empirically proved in many studies (Cashmore \& Goodnow, 1985; Okagaki \& Bevis, 1999; Whitbeck \& Gecas, 1988).

\section{SCHWARTZ'S VALUE THEORY}

We decided to choose the value theory and measure of Schwartz (Schwartz, 2006; Schwartz, Melech, Lehmann, Burgess, \& Harris, 2001). Based on the study of different population groups in 60 countries, Schwartz distinguished 10 types of motivational values which can be recognized in every culture (Schwartz, 1992; Schwartz \& Bardi, 2001). We summarized the content of these values as follows: power as people's social status, their control over other people and resources; achievement as personal success based on social standards; hedonism as pleasure, sensuous satisfaction; stimulation as the excitement over challenges and novelty; self-direction as independence in thought and action; universalism as understanding, tolerance and concern for the happiness of other people; benevolence as preserving and improving the welfare of close relatives; tradition as respect and compliance with principles, culture and religious customs; conformity as restraining actions and impulses that can harm other people or violate social expectations; and security as safety and stability of society. These 10 values can be organized along two bipolar axes, each of which contrasts two higher-order domains: 1) Conservatism (security, conformity, tradition) versus Openness to change (self-direction, stimulation); and 2) Self-enhancement (power, achievement) versus Self-transcendence (universalism, benevolence) (Fig. 1). 
All values are related to each other. Together they form a circular structure where each value is directly associated with adjacent values and is the reverse of the opposite value in the circle. So, one can easily pursue the adjacent values with the same action but cannot simultaneously pursue the opposite values in the circle (Schwartz, 1992).

\section{CURRENT STUDY}

Based on the written theories, we can say that the level of value agreement between parents and children is the result of the value transmitting process. On the one hand, the transmitting process shows the values that parents want to transmit to their children, while on the other hand it shows the level of acceptance by adolescents. However, in this article we do not study the mechanism of value transmission in families. Our aim in the conducted study was: 1) to analyse and compare the similarities and differences between the value system of adolescents and their parents (concerning gender difference); 2) to study expectations of parents toward children and preferences of children.

\section{HYPOTHESES}

Our first hypothesis was that Vietnamese parents' values and children's ones will be highly congruent. But in light of the general movement in the current context of integration and development, the second hypothesis was that even though Vietnamese young people respect their parents' values, they tend to change and prefer some new values rather than traditional ones.

\section{PARTICIPANTS AND PROCEDURE}

The study was conducted in Hanoi, Hue and Ho Chi Minh City (Saigon), from January to April in 2014. Data were gathered both from adolescents at average-ranking middle and high schools and their parents. The adolescents were asked to complete the PVQ-40 questionnaire. After that, the PVQ-40 questionnaire was sent to parents (with the support of the school teachers). Each adolescent's father and mother separately completed the questionnaire. After cleaning the data, we kept only those families having three questionnaires from all members: 742 adolescents ( $41.50 \%$ boys) from 14 to 18 years old $\left(M_{\text {age }}=16\right.$, $\left.S D_{\text {age }}=1.40\right), 742$ fathers from 35 to 70 years old $\left(M_{\text {age }}=47.30, S D_{\text {age }}=5.70\right)$, and 742 mothers from 33 to 62 years old $\left(M_{\text {age }}=44.10, S D_{\text {age }}=5.50\right)$.

\section{MEASURE}

The Portrait Values Questionnaire (PVQ-40) (Schwartz et al., 2001) consists of 40 items that are

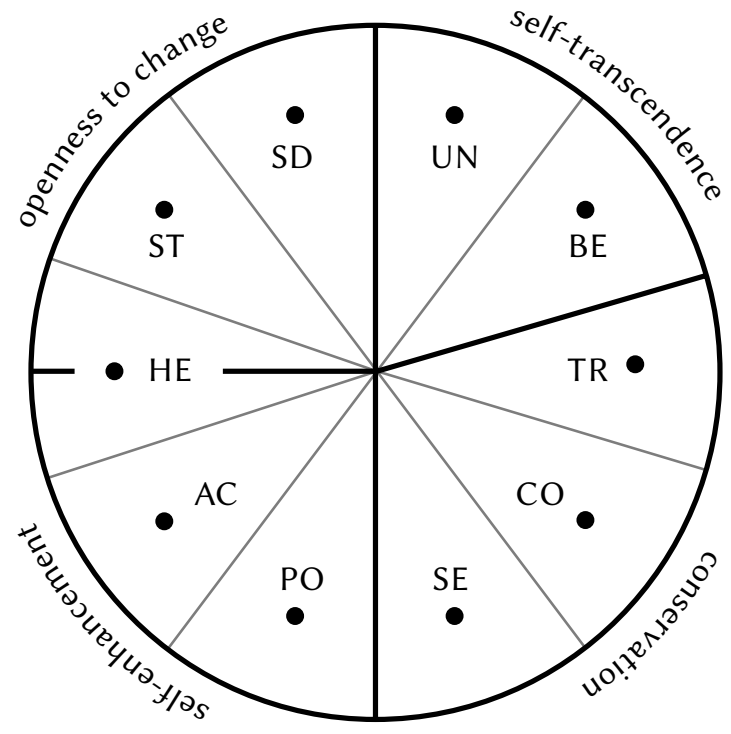

Values in Vietnam

Note. Power (PO), Achievement (AC), Hedonism (HE), Stimulation (ST), Self-direction (SD), Universalism (UN), Benevolence (BE), Tradition (TD), Conformity (CO), Security (SE).

Figure 1. Circle of 10 basic values (source: Schwartz, 1992).

presented in the form of short verbal portraits that describe 40 different people. PVQ-40 was translated into Vietnamese by a group of Vietnamese and Polish lecturers (Różycka-Tran, Żemojtel-Piotrowska, \& Truong, 2013), and adapted to Vietnamese culture on a representative sample (Różycka-Tran, Truong, Cieciuch, \& Schwartz, 2015).

Each portrait describes a person's goals, aspirations, or desires, which point implicitly to the importance of a value. Some items as an example: "She/he thinks it is important that everybody should be treated equally in the world. She/he believes that everyone should have equal opportunities in life" (universalism); "She/he looks for every chance to have fun. It is important to her/him to do things that give her/ him pleasure" (hedonism); "It is important to her/him to be rich. She/he wants to have a lot of money and expensive things" (power). For each portrait, the respondents answered the question "How much is this person like you?" on a scale from 1 (not like me at all) to 6 (very much like me).

Additionally we used a list of 28 attitudes and features to find out which features parents often implement in their children, and which features or attitudes the children already have. The parents have to answer two questions (on a scale from 1 to 6): "At which level do you encourage your children to have these features below?" and "In your opinion, at which level do your children have these features already?" Also children have to answer two questions (on a scale from 1 to 6): "At which level do your parents encourage you to have these features below?" and "In your opinion, at which level do you have these features already?", as an example: flexible and 
Table 1

Mean ratings of values: fathers, mothers and children $(N=2226)$

\begin{tabular}{lcccrrr}
\hline \multicolumn{1}{c}{ Values } & Children & Fathers & Mothers & \multirow{2}{*}{$F$} & $p$ \\
\cline { 2 - 4 } & $M(S D)$ & $M(S D)$ & \multicolumn{1}{c}{$M(S D)$} & & .024 \\
\hline Universalism & $4.32(0.82)$ & $4.21(0.82)$ & $4.23(0.78)$ & 3.72 & .578 \\
Benevolence & $4.29(0.72)$ & $4.25(0.79)$ & $4.26(0.77)$ & 0.54 & $<.001$ \\
Tradition & $3.74(0.78)$ & $4.22(0.76)$ & $4.32(0.72)$ & 119.85 & $<.10$ & .001 \\
Conformity & $4.13(0.77)$ & $4.26(0.77)$ & $4.27(0.73)$ & $4.55(0.74)$ & 68.91 & $<.001$ \\
Security & $4.08(0.81)$ & $4.42(0.82)$ & $3.18(0.99)$ & 10.40 & $<.001$ \\
Power & $3.34(1.08)$ & $3.42(0.95)$ & $3.82(0.89)$ & $3.65(0.92)$ & 8.10 & $<.001$ \\
Achievement & $3.82(0.98)$ & $3.53(0.99)$ & $3.48(0.98)$ & 68.04 & $<.001$ \\
Hedonism & $4.04(1.05)$ & $3.38(0.95)$ & $3.17(1.00)$ & 41.89 & $<.001$ \\
Stimulation & $3.64(0.98)$ & $4.06(0.81)$ & $3.92(0.80)$ & 10.05 & $<.001$ \\
Self-direction & $4.10(0.79)$ & & &
\end{tabular}

creative, humorous, aspirational, know how to manage money.

\section{RESULTS}

\section{COMPARING VALUES OF FATHERS, MOTHERS AND CHILDREN}

In the first step, we calculated the mean ratings of 10 motivational values based on Schwartz's model

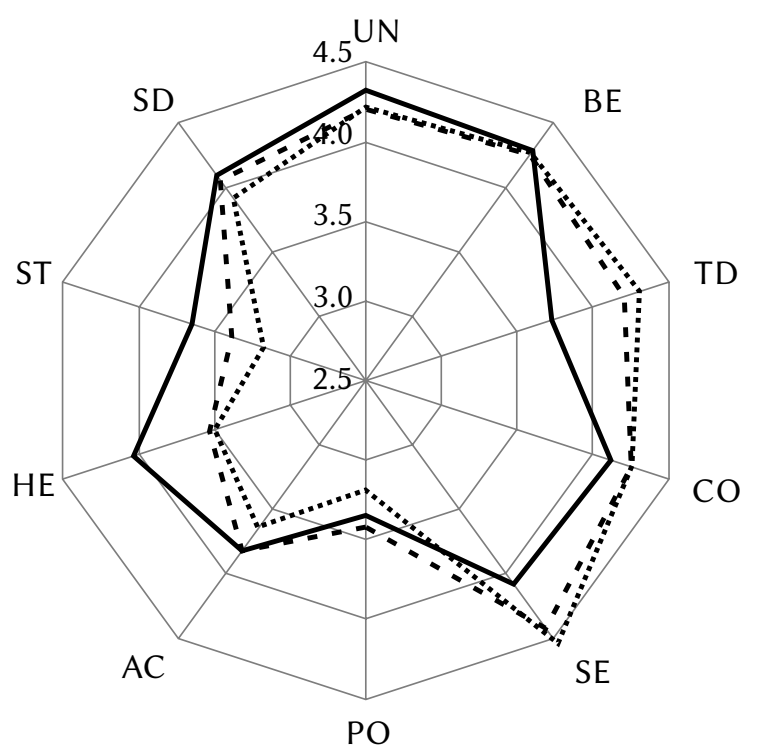

.. - Father - Children -...... Mother

Note. Power (PO), Achievement (AC), Hedonism (HE), Stimulation (ST), Self-direction (SD), Universalism (UN), Benevolence (BE), Tradition (TD), Conformity (CO), Security (SE).

Figure 2. Comparing mean ratings of basic values: fathers, mothers and children. gathered from adolescents, fathers and mothers and their children. The results are shown in Table 1.

When comparing the mean ratings of values in these groups (ANOVA), only the value of benevolence has no significant difference. Parents aim at the values of tradition, conformity and security significantly higher than their children; while children aim at the values of hedonism, stimulation, self-direction and universalism significantly higher than their parents (Fig. 2).

Although there are many similarities in the value scale of fathers and mothers, there are still some differences: mothers prefer the values of security and tradition more than fathers (security: $M=4.55$, $M=4.42, p<.001$; tradition: $M=4.32, M=4.22, p<.001$ ). In contrast, fathers tends to respect the values of power, achievement and stimulation more than mothers (power: $M=3.42, M=3.18, p<.001$; achievement: $M=3.82, M=3.65, p<.001$; stimulation: $M=3.38$, $M=3.17, p<.001)$. Because such a result could reflect gender differences, we compared male and female children, where we found not as many differences as between fathers and mothers (Fig. 3).

Student $t$-test comparisons showed that male adolescents prefer self-direction and achievement significantly more, while females value security more. There were no significant differences between two genders in the rest of values.

\section{THE HIERARCHY OF VALUES}

Next, we ranked all values in order of highest to lowest mean ratings for each respondent's group. The hierarchy of values of children, fathers and mothers is presented in Table 2 .

As can be seen in Table 2, there is a difference in the hierarchy of values between parents and chil- 
dren because of tradition, security, self-direction and hedonism. Parents value security and tradition the most, self-direction moderately and hedonism the least. Children value self-direction the most, hedonism moderately and tradition the least.

Comparing the mean ratings of the four higher-order values based on Schwarz's value theory, we found that: Self-transcendence values which are related to the concern for the rights and welfare of others are quite high for both groups (adolescents and parents) and not significant, while the self-enhancement values which emphasize the pursuit of power and personal success are low for both groups but significantly higher for adolescents. Conservatism values are higher for parents, while openness to change values are more important for adolescents (Table 3).

\section{THE RELATIONSHIP BETWEEN VALUE ORIENTATIONS AMONG FAMILY MEMBERS}

In order to evaluate the relationship between value orientations among family we categorized all members into different classes: father-mother, father-son, father-daughter, mother-son and mother-daughter. For each value we calculated Pearson's correlation coefficient between father, mother and their child. The results are shown in Table 4.

As shown in Table 4, the value orientations of the family members are directly correlated with each other for all values. In general, the correlations between values of mother-daughter pairs are higher than father-daughter pairs, and correlations in father-son pairs are higher than mother-son pairs. For example, a mother's values of tradition and power have no influence on these values of her son, but are significantly correlated with these values of her daughter. Values of achievement and self-direction of the father are

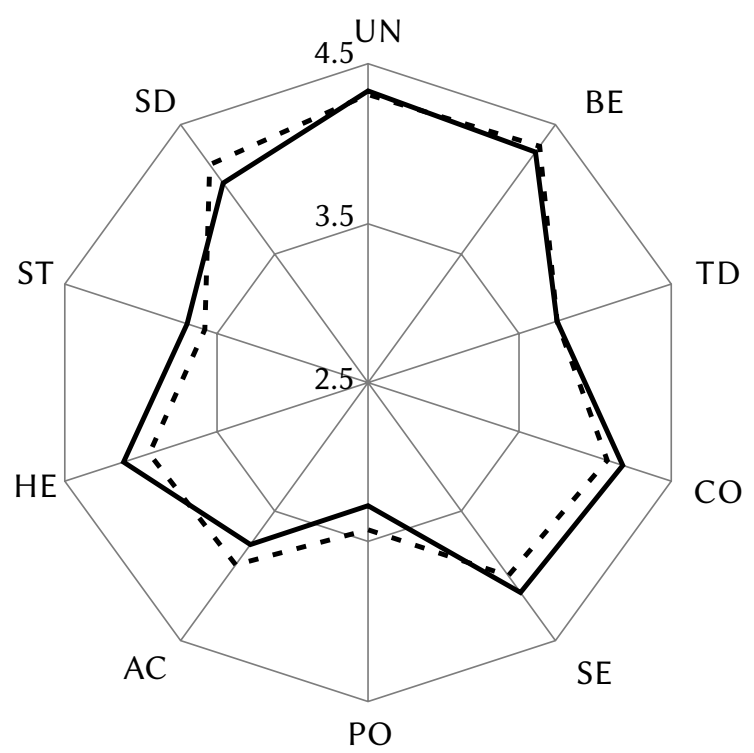

Values in Vietnam

$$
\text { - - Boys - Girls }
$$

Note. Power (PO), Achievement (AC), Hedonism (HE), Stimulation (ST), Self-direction (SD), Universalism (UN), Benevolence (BE), Tradition (TD), Conformity (CO), Security (SE).

Figure 3. Comparing the values of male and female children.

correlated with these values in his son more stronger than in his daughter. Particularly for the universalism value, the correlation between daughters and parents is stronger than sons and parents.

\section{ATTITUDES AND FEATURES TRANSFERRED BY PARENTS}

The fact that parents often transfer to their children some attitudes and features reflects the tendency to require children preferring the same values (respect-

Table 2

The hierarchy of values: children, fathers and mothers $(N=2226)$

\begin{tabular}{lcccc}
\hline Level & Rank & Children & Fathers & Mothers \\
\hline I & 1 & Universalism & Security & Security \\
High & 2 & Benevolence & Conformity & Tradition \\
& 3 & Conformity & Benevolence & Conformity \\
II & 4 & Self-direction & Tradition & Benevolence \\
Moderate & 5 & Security & Universalism & Universalism \\
& 6 & Hedonism & Self-direction & Self-direction \\
III & 7 & Achievement & Achievement & Achievement \\
Low & 8 & Tradition & Hedonism & Hedonism \\
& 9 & Stimulation & Power & Power \\
\hline
\end{tabular}


Table 3

The higher-order values: children, fathers and mothers $(N=2226)$

\begin{tabular}{|c|c|c|c|c|c|}
\hline & Children & Fathers & Mothers & $F$ & $p$ \\
\hline Self-transcendence & $\begin{array}{l}4.30 \\
0.66\end{array}$ & $\begin{array}{l}4.22 \\
0.74\end{array}$ & $\begin{array}{l}4.24 \\
0.71\end{array}$ & 2.51 & .081 \\
\hline Conservatism & $\begin{array}{l}3.99 \\
0.63\end{array}$ & $\begin{array}{l}4.22 \\
0.74\end{array}$ & $\begin{array}{l}4.38 \\
0.62\end{array}$ & 74.73 & $<.001$ \\
\hline Openness to change & $\begin{array}{l}3.86 \\
0.77\end{array}$ & $\begin{array}{l}3.72 \\
0.76\end{array}$ & $\begin{array}{l}3.54 \\
0.79\end{array}$ & 31.60 & $<.001$ \\
\hline Self-enhancement & $\begin{array}{l}3.73 \\
0.84\end{array}$ & $\begin{array}{l}3.59 \\
0.79\end{array}$ & $\begin{array}{l}3.43 \\
0.83\end{array}$ & 23.94 & $<.001$ \\
\hline
\end{tabular}

Table 4

Pearson correlation (r) for each value between parent-child pairs

\begin{tabular}{lccccc}
\hline \multicolumn{1}{c}{ Values } & Father-mother & Father-son & $\begin{array}{c}\text { Father } \\
\text { daughter }\end{array}$ & Mother-son & $\begin{array}{c}\text { Mother- } \\
\text { daughter }\end{array}$ \\
\hline Universalism & $.51^{* *}$ & $.20^{* *}$ & $.21^{* *}$ & $.23^{* *}$ & $.30^{* *}$ \\
Benevolence & $.50^{* *}$ & $.22^{* *}$ & $.11^{*}$ & $.15^{*}$ & $.22^{* *}$ \\
Tradition & $.43^{* *}$ & $.15^{* *}$ & $.15^{* *}$ & .41 & $.21^{* *}$ \\
Conformity & $.34^{* *}$ & $.18^{* *}$ & $.12^{*}$ & $.11^{*}$ & $.25^{* *}$ \\
Security & $.46^{* *}$ & $.22^{* *}$ & $.12^{*}$ & $.16^{*}$ & $.25^{* *}$ \\
Power & $.38^{* *}$ & $.15^{*}$ & $.13^{* *}$ & .36 & $.13^{* *}$ \\
Achievement & $.44^{* *}$ & $.22^{* *}$ & $.13^{*}$ & $.12^{*}$ & $.16^{* *}$ \\
Hedonism & $.39^{* *}$ & $.20^{* *}$ & $.16^{* *}$ & $.20^{* *}$ & $.19^{* *}$ \\
Stimulation & $.40^{* *}$ & .32 & $.33^{* *}$ & $.13^{*}$ & $.14^{*}$ \\
Self-direction & $.45^{* *}$ & $.26^{* *}$ & $.17^{* *}$ & $.21^{* *}$
\end{tabular}

ed by parents). According to factor analysis (Varimax with Kaiser normalization), we obtained five components (groups of features) varying from .467 to .798 (eigenvalue greater than 1), explaining $53.80 \%$ of variance. All particular features as well as five components are presented in Table 5 .

According to the comparison of mean ratings of fathers, mothers and children's evaluation, we obtained the result that there is no difference between fathers and mothers; however, there are some differences between the evaluations of parents and their children (Table 6).

In all groups of features (except group 2), fathers, mothers and children evaluated that children did not reach the level of parents' expectation. Only in group 2 did adolescents highly evaluate themselves as having features such as: imaginative, flexible and creative, lively and enthusiastic, adventurous, optimistic, self-confident, humorous, courageous and aspirational, which appeared stronger than parents encourage them to have. It means that children prefer such features, irrespective of parents' wishes.
When arranging these groups of features in order of priority (from the most to the least important), which parents often encourage children to have, there is quite high consistency between parents and children: group 3, group 1, group 4, group 5 and group 2. However, when assessing the importance of all groups of features, all family members respect group 1 the most, which includes: loving, respect of self and others, civility, benevolence toward parents, merciful, grateful, sharing and helping, honest, responsible, modest. These features are closely related to the values of universalism, benevolence and conformity highly valued by both parents and children on Schwartz's value scale.

\section{DISCUSSION AND CONCLUSIONS}

As stated above, the purpose of this study was to analyse the motivational value system of Vietnamese parents and adolescents. We were interested in similarities and differences between the values of parents 
Table 5

Rotated component matrix

\begin{tabular}{|c|c|c|c|c|c|}
\hline \multirow[t]{2}{*}{ Features and attitudes } & \multicolumn{5}{|c|}{ Components } \\
\hline & $(1)$ & $(2)$ & (3) & (4) & $(5)$ \\
\hline Loving & .735 & & & & \\
\hline Respect self and others & .673 & & & & \\
\hline Civility & .660 & & & & \\
\hline Benevolence toward parents & .643 & & & & \\
\hline Merciful & .619 & & & & \\
\hline Grateful & 611 & & & & \\
\hline Sharing and helping & .597 & & & & \\
\hline Honest & .551 & & & & \\
\hline Responsible & .479 & & & & \\
\hline Modest & .467 & & & & \\
\hline Imaginative & & .659 & & & \\
\hline Flexible and creative & & .621 & & & \\
\hline Lively and enthusiastic & & .599 & & & \\
\hline Adventurous & & .597 & & & \\
\hline Optimistic & & .566 & & & \\
\hline Self-confident & & .565 & & & \\
\hline Humorous & & .563 & & & \\
\hline Courageous & & .556 & & & \\
\hline Aspirational & & .509 & & & \\
\hline Studious & & & .789 & & \\
\hline Good at studying & & & .750 & & \\
\hline Diligent & & & .601 & & \\
\hline Willing & & & .537 & & \\
\hline Know how to stay healthy & & & & .749 & \\
\hline Laborious & & & & .712 & \\
\hline Know how to manage money & & & & & .798 \\
\hline Know how to make money & & & & & .781 \\
\hline Independent and self-directed & & & & & .547 \\
\hline
\end{tabular}

and children, and also we wanted to know which values parents want to transfer to their children, as well as whether children accept those values. Although most value transmission studies have examined both parents together (as a unit), this study considered fathers' and mothers' values separately; in that way the potential variation in adolescents' acceptance represented by the congruence of fathers and mothers is taken into account, which was also suggested by Cavalli-Sforza and Feldman (1981). In general, the value hierarchy of Vietnamese fathers and mothers is almost the same (see Table 2). Also there are similar- ities between parents' and children's values (see Table 1: highly valued universalism and benevolence as opposed to power and achievement; and Table 4: the value orientations of the family members are directly correlated with each other for all values). We can conclude that there is a close relationship and mutual interaction between Vietnamese husband and wife in the family, which not only creates a common value orientation of each couple, but also has a certain influence on their children's general value orientation.

The value transmission from parents to children is a concept that has been proved in many studies 
Table 6

Groups of features which parents often encourage children to have

\begin{tabular}{|c|c|c|c|c|c|c|}
\hline & \multirow[t]{2}{*}{$\begin{array}{l}\text { Components/Group } \\
\text { of features }\end{array}$} & $\begin{array}{l}\text { Children's } \\
\text { evaluation }\end{array}$ & $\begin{array}{c}\text { Fathers' } \\
\text { evaluation }\end{array}$ & $\begin{array}{l}\text { Mothers' } \\
\text { evaluation }\end{array}$ & \multirow[t]{2}{*}{$F$} & \multirow[t]{2}{*}{$p$} \\
\hline & & $M(S D)$ & $M(S D)$ & $M(S D)$ & & \\
\hline \multirow[t]{2}{*}{ (1) } & $\begin{array}{c}\text { Parents encourage children } \\
\text { to have }\end{array}$ & $4.70(0.76)$ & $4.90(0.74)$ & $4.95(0.69)$ & 24.43 & $<.001$ \\
\hline & Children already have & $4.62(0.64)$ & $4.75(0.71)$ & $4.78(0.68)$ & 11.78 & $<.001$ \\
\hline \multirow[t]{2}{*}{ (2) } & $\begin{array}{c}\text { Parents encourage children } \\
\text { to have }\end{array}$ & $3.61(0.91)$ & $4.05(0.90)$ & $4.08(0.84)$ & 64.33 & $<.001$ \\
\hline & Children already have & $3.94(0.79)$ & $4.09(0.83)$ & $4.01(0.81)$ & 6.02 & .002 \\
\hline \multirow[t]{2}{*}{ (3) } & $\begin{array}{c}\text { Parents encourage children } \\
\text { to have }\end{array}$ & $5.03(0.81)$ & $4.97(0.79)$ & $5.02(0.74)$ & 0.93 & .394 \\
\hline & Children already have & $4.02(0.89)$ & $4.56(0.85)$ & $4.50(0.85)$ & 85.83 & $<.001$ \\
\hline \multirow[t]{2}{*}{ (4) } & $\begin{array}{c}\text { Parents encourage children } \\
\text { to have }\end{array}$ & $4.58(1.06)$ & $4.74(0.98)$ & $4.80(0.90)$ & 9.53 & $<.001$ \\
\hline & Children already have & $3.81(1.14)$ & $4.26(1.08)$ & $4.23(1.05)$ & 40.08 & $<.001$ \\
\hline \multirow[t]{2}{*}{ (5) } & $\begin{array}{c}\text { Parents encourage children } \\
\text { to have }\end{array}$ & $4.30(1.10)$ & $4.31(1.04)$ & $4.36(1.01)$ & 0.70 & .496 \\
\hline & Children already have & $4.11(1.06)$ & $4.18(1.05)$ & $4.15(1.03)$ & 1.01 & .364 \\
\hline
\end{tabular}

before, and traditionally is considered as a unidirectional influence process (Kuczynski \& Hildebrandt, 1997), where the parental influence has been proved to be much clearer and stronger than the children's influence (Kohn, Slomczynski, \& Schoenbach, 1986; Vollebergh, Iedema, \& Raaijmakers, 2001). Though children may influence their parents as well (Ambert, 1992), there is no evidence of such a process in this study. We therefore expected that parental agreement would support children's motivation to accept parents' values. Barni, Ranieri, Scabini, and Rosnati (2011) suggested that the agreement between fathers and mothers makes their value messages clearer and easier for children to perceive. Grusec and Goodnow (1994), when they studied children's motivation to accept parental values, also found out that agreement between parents, warmth and closeness between parents and their children are important contributors to increase children's willingness to comply with parental wishes.

The similarities between parents and children show that these common values deeply reflect Vietnamese culture's characteristics that have been stated in many studies on Vietnamese identities before, a community culture which appreciates the respect and concern for the interests of others as opposed to power and personal success (Tran Dinh Huou, 1994). The similarities between adolescents and their parents (see Tables 2, 3) represent those national characteristics again. Both generations value universalism, benevolence and conformity more than stimulation, self-direction, achievement and hedonism. This characteristic represents a tendency to preserve rather than to change in development in both generations, which is also considered an important and powerful trend of Vietnamese culture (Tran Ngoc Them, 2004).

Beside the similarities, the differences between two generations can be seen in two aspects: adolescents aim at openness to change values (self-direction, stimulation) more than conservatism (security, conformity, tradition). The value of hedonism which reflects both the openness to change and self-enhancement is also more preferred by adolescents. This shows the tendency to change values of the young generation, and also the fact that children's values can be formed by other factors than parents. Though Vietnamese young people know that their parents expect them to prefer traditional values (as thought by many Vietnamese generations before), they are more interested in pleasure, excitement, satisfaction, new experiences, self-direction and self-determination, and tend to resist conservative values including tradition, conformity and security. Marcia (1966) mentioned the concept of adolescents' active struggle to make commitments, which is shown clearly in their relatively accurate perception of parents' values. She also noted that these values are not automatically accepted by adolescents; although parents' wishes are still important, they attempt a compromise among parents' wishes, society's demands, and their own capabilities.

In the context of integration and development these days, many foreign companies have invested 
and operated in Vietnam, many international universities have been established, and also many culture exchange programmes from around the world are shown on TV. These have all brought new values to Vietnam, beside those traditional ones, as shown clearly in our results: adolescents pay less attention to the values of tradition and security, moving towards self-determination, new challenges and self-enhancement. Even though one of the remarkable characteristics of the Vietnamese is that they honour traditional customs (Dao Duy Anh, 2000) and do not respect individuality (Tran Dinh Huou, 1994), it seems that the young generation and also collectivistic societies these days prefer more individualistic values, which is consistent with other studies (Różycka-Tran et al., 2013).

Though it is an inevitable trend for the youth to respect more the values of self-direction and stimulation, it is also a major cause of generational conflict in Vietnam these days. Adolescence is a very important phase for formation of values because it is the time of identity development, characterised by tension between an increasing need for autonomy and increasing conformity to societal expectations (Padilla-Walker, 2007). For that reason, if parents prevent their children from seeking independence or new experiences, they will have to face conflict and resistance, which will hinder adolescents in adopting other values from them. We therefore suggest that the young people might be more willing to accept their parents' values if they are encouraged to seek self-determination and personal achievement. Another study also showed that a higher level of children's openness to and acceptance of parental messages can be achieved if these messages are not perceived as being 'threatening' to autonomy (Grusec \& Goodnow, 1994). In other words, children may choose to accept or to reject the values they perceived from parents.

As mentioned before, adolescents perceived their parents as wanting them to endorse primarily conservative values, whereas they were more open to new experiences and challenges. Thus, adolescents declined to accept conservative values, which seems to be reasonable since adolescence is an important period involved in exploring and developing children's autonomous and independent identity (Barni et al., 2011) and the values of openness to change clearly promote the pursuit of independence. On the other hand, parents in general and Vietnamese parents in particular must have responsibility for their children. They therefore have to consider the security and rules that are needed during adolescence, as well as their children's increasing need for autonomy (Scabini, Marta, \& Lanz, 2006). For that reason, it would be surprising and even inappropriate, not only in Vietnam but worldwide, to see an opposite perceptual pattern in which adolescents perceive themselves to be conservative and their parents tend to promote enjoyment and search for novelty (Barni, 2009).

When comparing the basic values of fathers, mothers and children, in our opinion the obtained results reflect the gender differences in Vietnam: men aim at power, achievement and stimulation more than women; conversely, women aim at the values of security and tradition. However, there are not as many differences between male and female children as between fathers and mothers. The reason might be that the social gender roles become significant after marriage. As found by Barni and Ranieri (2010), parents' and adolescents' values seems to become more similar at the end of the transition to adulthood, which is also consistent with our hypothesis.

In our study, the correlations between values of mother-daughter pairs are higher than father-daughter pairs, and those of father-son pairs are higher than mother-son pairs (e.g. a mother's values of tradition and power have no influence on these values of her son, yet significantly correlated with these values of her daughter; values of achievement and self-direction of a father are correlated with these values of his son more strongly than those of his daughter). In addition, for the universalism value only, girls had a slightly higher endorsement than boys, which provides no clear evidence for the influence of children's gender on the acceptance of parental values (Barni et al., 2011).

To conclude, the formation of values in adolescents occurs while they interact with their parents and friends, in a certain social environment. Therefore the value system of adolescents reflects not only the value system of parents, but also the values preferred by young people in a specific social context. The fact that young people prefer openness to change rather than conservative values reflects the youth's trend in the changing value system, consistent with the general movement in current society (where people are not only obedient, hard-working, diligent and willing to sacrifice for others, but also aspirational, self-directed, optimistic, cheerful and happy). The direct correlations of all values between fathers, mothers and children reflect the strong relationship and interaction between all members of the family. Therefore, in order to transfer values to the young generation, parents should first elaborate the value orientation more appropriately in the current context of integration and development.

\section{LIMITATIONS AND FUTURE RESEARCH}

The study examined a large number of families with parents and their children. This allowed the correlation between values of family members to be analysed objectively and to some extent accurately. 
However, this study certainly has some limitations. Firstly, it used a cross-sectional design as an observational method. Hence all of our analysis can only be carried out at a single point in time. We will not be able to consider the past or future relationship between parents' and children's values. Even though this study allowed researchers to compare many different variables at the same time, longitudinal studies are still needed in order to truly gain an in-depth understanding of the interactive nature of value transmission from parents to their children and also the development of adolescents' value orientation over time. Secondly, our data were collected from Hanoi, Hue and Ho Chi Minh City. While Hanoi and Ho Chi Minh City are two of the largest cities in Vietnam, which have "first-tier city" status, meaning that they not only have provincial status but also enjoy certain special privileges and priority from the central government in budget allocation and infrastructure investments, Hue was the capital city of Vietnam for approximately 150 years during the feudal period (1802-1945) and is small but famous as a cultural centre of Vietnam (Nguyen Dac Xuan, 2009). As we can see, although the sample was large, it might not be so representative. Since we cannot exclude the possibility that larger samples from other areas of Vietnam, especially in rural and undeveloped areas, might provide different results, greater caution with more effort is needed when generalising our study to all Vietnamese families as well as adolescents. Thirdly, the study considered the similarities between values of parents and children as a result of the transmission of values. However, this is just partially true, because although most parents want to transmit to their children the values that they themselves also aim at (Knafo \& Schwartz, 2001, 2004), there are also parents who recognize the trend of changing values of modern society and encourage children to create different values other than those they think highly of. For that reason, the differences between their values are not necessarily the result of either failed value transmission or any other factors than parents. Moreover, adolescents' values formation is generally under the great influence of the movement of the current society, not their families; such an impact also has not been clarified clearly in this study.

It would be interesting for future research to adopt multiple methods and consider not only cross-sectional studies but also longitudinal instruments which could help us gain a fully comprehensive knowledge about the transmission of values as well as how the value orientation changes in adolescents over time. Moreover, according to the two steps of transmission described in Grusec and Goodnow's model, analysing adolescents' acceptance together with their accuracy in perception can also be seen as an interesting approach, because even though children are willing to accept the values parents want to transmit, a high level of parents-children value congruence might not be created if they perceive those values incorrectly. In addition, we also want to be able to carry out another study in the future related to the values that parents themselves do not directly aim at, but which they still want their children to have as a compensation for their own unsatisfied youth, and also the values that parents do not want to be formed in their children but which they still receive from friends and from the global entertainment and media industry in the current cross-cultural context.

The work of Truong Thi Khanh Ha was supported by grants VI 1.1-2012.15 from the Vietnam National Foundation for Science and Technology Development (NAFOSTED).

We would like to thank Tran Ha Thu, Dau Minh Long and Nguyen Dinh Phong for gathering the data.

\section{References}

Ambert, A. M. (1992). The effect of children on parents. New York: Haworth Press.

Anh, D. D. (2000). General history of Vietnamese culture (Viet Nam van hoa su cuong). Hanoi: Vietnam Writers' Association Publishing House.

Barni, D. (2009). Trasmettere valori. Tre generazioni familiari a confronto [Transmitting values. A comparison between three family generations]. Milano: Unicopli.

Barni, D., \& Ranieri, S. (2010). La trasmissione dei valori in famiglia: una misura diadica della similarità tra genitori e figli [Value transmission in the family: a dyadic measure of parent-child value similarity]. In: C. Galimberti \& G. Scaratti (eds.), Epistemologie della complessità nella ricerca psicologica [Epistemologies of complexity in psychological research] (pp. 63-95). Milano: Contributi di Psicologia.

Barni, D., Ranieri, S., Scabini, E., \& Rosnati, R. (2011). Value transmission in the family: do adolescents accept the values their parents want to transmit? Journal of Moral Education, 40, 105-121.

Cashmore, J. A., \& Goodnow, J. J. (1985). Agreement between generations: A two-process approach. Child Development, 56, 493-501.

Cavalli-Sforza, L. L., \& Feldman, M. (1981). Cultural transmission and evolution: a quantitative approach. Princeton: Princeton University Press.

Erikson, E. H. (1968). Identity: Youth and crisis. New York: Norton.

Grusec, J. E., \& Goodnow, J. J. (1994). Impact of parental discipline methods on the child's internalization of values: A reconceptualization of current points of view. Developmental Psychology, 30, 4-19. Knafo, A., \& Schwartz, S. H. (2001). Value socialization in families of Israeli-born and Soviet-born 
adolescents in Israel. Journal of Cross-Cultural Psychology, 32, 213-228.

Knafo, A., \& Schwartz, S. H. (2004). Identity formation and parent-child value congruence in adolescence. British Journal of Developmental Psychology, 22, 439-458.

Kohn, M. L., Slomczynski, K. M., \& Schoenbach, C. (1986). Social stratification and the transmission of values in the family: A cross-national assessment. Sociological Forum, 1, 73-102.

Kuczynski, L., \& Hildebrandt, N. (1997) Models of conformity and resistance in socialization theory. In: J. E. Grusec \& L. Kuczynski (eds.), Parenting and children's internalization of values: a handbook of contemporary theory (pp. 227-256). New York: Wiley.

Kuczynski, L., Marshall, S., \& Schell, K. (1997). Value socialization in a bidirectional context. In: J. E. Grusec \& L. Kuczynski (eds.), Parenting and the internalization of values: A handbook of contemporary theory (pp. 23-50). New York: Wiley.

Marcia, J. E. (1966). Development and validation of ego-identity status. Journal of Personality and Social Psychology, 3, 551-558.

Marcia, J. E. (1980). Identity in adolescence. In: J. Adelson (ed.), Handbook of adolescent psychology. New York: Wiley.

Okagaki, L., \& Bevis, C. (1999). Transmission of religious values: Relations between parents' and daughters' beliefs. Journal of Genetic Psychology, 160, 303-318.

Padilla-Walker, L. (2007) Characteristics of motherchild interactions related to adolescents' positive values and behaviors. Journal of Marriage and Family, 69, 675-686.

Różycka-Tran, J., Truong, T. K. H., Cieciuch, J., \& Schwartz, S. H. (2015). Universals and Specifics of the Structure and Hierarchy of Basic Human Values in Vietnam. Cultural Diversity \& Ethnic Minority Psychology (in revision).

Różycka-Tran, J., Żemojtel-Piotrowska, M., \& Truong, T. K. H. (2013). Schwartz' personal and cultural values in Polish and Vietnamese cultures. Psychologia Spoteczna, 4, 396-407.

Scabini, E., Marta, E., \& Lanz, M. (2006). The transition to adulthood and family relations. An intergenerational perspective. London: Psychology Press.

Schwartz, S. H. (1992). Universals in the content and structure of values: Theoretical advances and empirical tests in 20 countries. In: M. P. Zanna (ed.), Advances in experimental social psychology, 25 (pp. 1-65). New York: Academic Press.

Schwartz, S. H. (2006). A theory of cultural value orientations: explication and applications. Comparative Sociology, 5, 137-182. DOI: 10.1163/ 156913306778667357

Schwartz, S. H., \& Bardi, A. (2001). Value hierarchies across cultures: Taking a similarities perspective. Journal of Cross-Cultural Psychology, 32, 268-290.
Schwartz, S. H., Melech, G., Lehmann, A., Burgess, S., \& Harris, M. (2001). Extending the cross-cultural validity of the theory of basic human values with a different method of measurement. Journal of Cross-Cultural Psychology, 32, 519-542.

Tran Dinh Huou. (1994). About finding out national cultural identity. To modernity from tradition. Hanoi: Culture Publishing House.

Tran Ngoc Them. (2004). Research on the Identity of Vietnamese Culture. Hanoi: World Publisher.

Vollebergh, W. A. M., ledema, J., \& Raaijmakers, Q. A. W. (2001). Intergenerational transmission and the formation of cultural orientations in adolescence and young adulthood. Journal of Marriage and the Family, 63, 1185-1198.

Whitbeck, L. B., \& Gecas, V. (1988). Value attributions and value transmission between parents and children. Journal of Marriage and the Family, 50, 829840.

Xuan N. D. (2009). 700 years of Thuan Hoa - Phu Xuan - Hue. Vietnam: The Publishing House Co. Ltd. 